\title{
Medicine between Expectations and Disappointments
}

\section{Sur Genel*}

University of Medicine and Pharmacy, IuliuHatieganu, Cluj-Napoca, Romania

\section{Keywords: Medicine; Expectations, Disappointments}

The authors have proposed to analyze the factors that lead to unequal access to health care services in most countries. There is a big difference between the health needs of individuals and the possibilities to provide them. In poor countries is practiced minimalist medicine, while in developed countries it promotes elitist medicine. The big difference between needs and possibilities make some diseases of poor people to put on guard all humanity. The authors question whether there is a possibility that certain diseases and their complications can be avoided. The answer is yes, but people must realize and respect certain principles of life and give up unhealthy habits. Access to health care must be unconditioned. The principle of "pay or die" must disappear. Medicine must be directed to the individual and his needs without compromising quality, promptitude and efficiency.

Many and miraculous have been discoveries of medicine over time. In the last few decades in medicine have made more discoveries than in the 2,000 years. All these marvelous discoveries have not made humanity to become healthier and happier. While some diseases have disappeared, others have appeared which unfortunately creates concern worldwide. An example is how Ebola was able to disturb the entire medical system in the world, without being currently adequate treatment options. Before Ebola AIDS devastated poor countries and reduced life expectancy of patients in rich countries.

Technical advances that have occurred in the world have given birth to civilization diseases. These diseases of civilization are related to the ecological crisis but also the modern style of living with stress, inactivity, and overeating. The WHO report from 2000 showed that "humanity is living dangerously"[1]. Although it is known that certain unhealthy habits such as smoking, drinking, sedentary lifestyle and unbalanced diet, leading to worsening of disease, people do not give up these habits. There is a big gap between what we know and what we do.

It maintains an uneven polarization of resources both in the states and at the global level. Access to healthcare is not equal. While in some areas people do not benefit either the minimum necessary in other areas there is an excessive care towards personalities. Unfortunately the great medical advances fail to reach all over the world. There is a tendency to rank health institutions in terms of value from the minimalist to the elite [2].

Unequal economic development of areas of the planet has led to social differences that are being felt and can create future problems. While a great part of rich world's population struggle to eat less, most of the population from poor areas have nothing to eat. In terms of social differences and resources polarization we are faced with an old stalemate "pay or die". Medical staff faces up to the problems in developing diagnostic and pitfalls in the treatment of diseases. Medical act should be conducted in close contact with the doctor-patientdisease axis. From this equation the patient should never be removed because it needs warm near claims promptly, responsibility, wants encouragement and hope. Diagnostic system with modern technology that aims to isolate the patient from contact with medical staff makes him to become more scared and hopeless. Communication of a serious diagnosis without empathize with the patient makes him have a negative experiences with questions that only him can not give an answer.

Recent advances in medicine have led to new hopes on the gray sky of human existence. The map of the human genome was deciphered in 2000 by Francis Collins and Craig Venter [3,4]. Genomic medicine redefines current conception about the disease and establishes the bases of individualized medicine. Over the time there have emerged two conceptions about the disease: one essentialist and other nominal In essentialist conception each disease is a distinct entity that occurs randomly as a simple fact of life, a biological error in a previously healthy person. It has a specific cause and it is manifested in a constant and similar form to different patients. In this conception treatment is directed to the disease and not to the patient and it is relatively the same in all patients. There is a cruel irony that the medicine, a profession so devoted to care of individuals, gives them from this perspective so little attention. In nominal concept disease is a result of the interaction between biological singularity of the patient and causative environmental agents. The origin of the disease has roots in ecological and genetics history of each individual. From this perspective it is understandable dictum that "there are no diseases but only patients". The possibility of similarity of manifestation in different patients is due to common schedule of genes [5].

The future belongs to genomic medicine which by using new scientific arguments supports the definitive integration of nominal concept. The disease is considered a disruption of complex networks that operate variable in different structure and periods and from one person to another. This integrative global concept about disease that it brings genomic medicine will allow a deep understanding of individual risk factor to disease manifestations and its treatment based on individual profiles. Thus, genomic medicine is an individualized medicine, personalized, predictive, preventive, proactive and participative.

Others important medical discoveries of the last decade grow hopes for a better life, so proceed to genetic manipulation in humans. For example, a team of researchers from France will introduce a gene therapy in a genetic disease leading to blindness. It was created transgenic mouse able to withstand the cancerous attacks. Is about to be selected longevity gene that allows individuals to live long but within normal parameters. From this point of view people tend to get the famous Methuselah who lived 940 years. By 2020 it is hoped that will appear robots about the size of a cell which will be able to clean

*Corresponding author: Sur Genel, University of Medicine and Pharmacy, IuliuHatieganu, Cluj-Napoca, Romania, E-mail: surgenel@yahoo.com

Received November 04, 2014; Accepted November 05, 2014; Published November 10, 2014

Citation: Genel S (2014) Medicine between Expectations and Disappointments. Pharm Anal Acta 5: e167. doi:10.4172/2153-2435.1000e167

Copyright: (c) 2014 Genel S. This is an open-access article distributed under the terms of the Creative Commons Attribution License, which permits unrestricted use, distribution, and reproduction in any medium, provided the original author and source are credited. 
up the blood vessels and transport drugs in certain places otherwise unapproachable. By $3 \mathrm{D}$ printer will be created organs which will be able to human transplantation, and these organs will not be rejected by the host body.

If all these great discoveries will be made available how many people will benefit from them? It is also asking the question: can a man imitate God in creation? The answer is absolutely not. Despite efforts of scientists it arise new diseases and new unknown issues that will be difficult to manage. While we can partially overcome microbial diseases, viral diseases lead to a high mortality. Maybe it will be able to beat cancer, but other diseases will appear as a side effect of treatment. Treatment itself should be reconsidered so that it can be beneficial in a disease but can cause other pathologies.

These findings are really beautiful and helpful but all individuals will have to benefit from them. It will have eliminated social inequality and will be promoted a healthy lifestyle. Medicine will be able to treat all patients who need treatment. First mission of a doctor is to treat and heal. Only so he justifies his being.

PAA Journal by published articles tried and partly succeeded in promoting healthy ideas about life and disease and to provide with readers the possibility of confrontation and scientific understanding of mechanisms and treatments.

\section{References}

1. WHO: The world health report 2000

2. WHO: World health report 2013

3. Jill Adams (2008) Sequencing human genome: the contributions of Francis Collins and Craig Venter. Nature Education 1:133.

4. Marc A Shampo, Robert A Kyle (2010) Francis S. Collins-Human Genome Project. Mayo ClinProc 85: e66-e67.

5. GOLD, Genomes OnLine Database. 